\title{
A Novel Genetic-based Optimization for Transmission Constrained Generation Expansion Planning
}

\author{
Iman Goroohi Sardou, Mohammad Taghi Ameli, Dr., Mohammad Sadegh Sepasian, Dr., \\ Mohammad Ahmadian, Dr. \\ Dept. of Electrical and Computer Engineering, Shahid Beheshti University, Tehran, Iran \\ E-mail:imangoroohi@gmail.com;ameli@pwut.ac.ir;sepasian@pwut.ac.ir;ahmadian@pwut.ac.ir
}

\begin{abstract}
Transmission constrained generation expansion planning (TC-GEP) problem involves decisions on site, capacity, type of fuel, and etc. of new generation units, which should be installed over a planning horizon to meet the expectations of energy demand. This may lead to adding or lightening transmission lines congestion. This paper presents an application of genetic algorithm (GA) to TC-GEP problem for simultaneously determination of new generation site, capacity and fuel type for a multi-period generation expansion plan. The objective function in this paper is to minimize the total generation cost which is composed of generation capital investment costs, operation and maintenance (O\&M) costs, outage cost, transmission losses costs and transmission enhancement costs. In this paper, also a new method is proposed for computing transmission enhancement costs. In addition a new approach is presented in this paper to determine
\end{abstract}

site and number of combined cycle power plants regarding to candidate units. The GA is applied to solve TC-GEP proble $m$ for 4 bus test system from Grainger \& Stevenson for a planning horizon of one year and the results are compared and validated against Enumeration Method (EM). Then GA is applied to solve TC-GEP problem for IEEE-RTS 24-bus test system for a planning horizon of three years and results are discussed.

Index Terms - Generation Expansion Planning, Genetic Algorithm, Probabilistic Production Simulation, Power Losses Cost, Transmission Constraints

\section{Nomenclature:}

$\mathrm{T} \quad$ Study period (in years)

$\overline{I G_{t}} \quad$ Discounted value of the generation capital investment costs (\$) in year $t$

$\overline{I T}_{t}^{\text {worst }} \quad$ Discounted value of the transmission capital investment costs (\$) in the period of year $t$ with the worst conditions

$I G_{t} \quad$ Generation capital investment costs (\$) in year $t$

$N_{p} \quad$ Total number of different types of power plants

$N_{k} \quad$ Total number of different types of units

$P G^{k} \quad$ Maximum capacity (MW) of a $\mathrm{k}^{\text {th }}$ type unit

$C I G F T_{p, b} \quad$ Part of $C I G F_{p, b}$ related to technical $\operatorname{cost}(\$)$

$C I G F L_{p, b} \quad$ Part of $C I G F_{p, b}$ related to land $\operatorname{cost}(\$)$

$C_{\text {CIGFP }}$ Part of $C I G F_{p, b}$ related to fuel supply piping $\operatorname{cost}(\$)$

$C I G F G C_{p, b}$ Part of $C I G F_{p, b}$ related to interconnection cost to the main grid (\$)

$C I G V T_{k, b} \quad$ Part of $C I G V_{k, b}$ related to technical $\operatorname{cost}(\$)$

$C I G V L_{k, b} \quad$ Part of $C I G V_{k, b}$ related to land $\operatorname{cost}(\$)$

$C I G V P_{k, b} \quad$ Part of $C I G V_{k, b}$ related to fuel supply piping $\operatorname{cost}(\$)$

$C I G V G C_{k, b}$ Part of $C I G V_{k, b}$ related to interconnection cost to the main grid (\$)

$I T_{t}^{\text {worst }}$

Transmission capital investment costs (\$) in worst period of year $t$ (period with the worst conditions) of the study period 


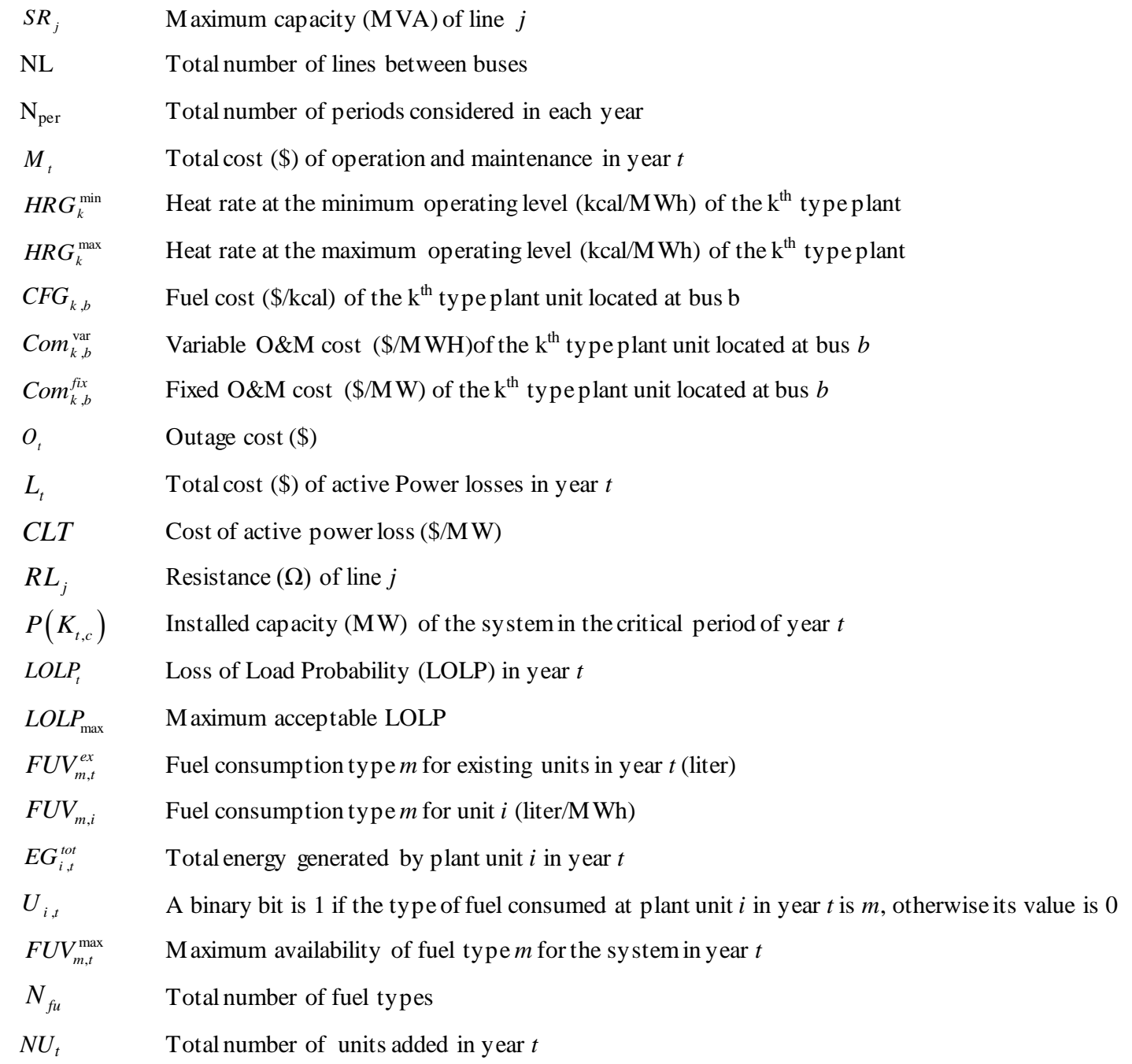

\section{Introduction}

Generation Expansion Planning (GEP) is the essential step in long-term planning problems, after properly forecasting the load for a specified future period. Generally, GEP is an optimization problem in which the objective is to decide the new generation plants in terms of what type and capacity they should be, where they should be installed and when to be invested, with the result that the cost function is minimized and various constraints are satisfied. GEP problem may be of a static type (for a specified stage, typically a year) or a dynamic type (for several stages in a specified period), concerning the stages under consideration for the planning horizon [1-3].

References [1,4-9] have used decomposition schemes to handle the problem complexity. Usually, such schemes divide the GEP problem into two sub-problems: the first is a single-bus GEP without considering transmission system; the next is a multi-bus GEP in which the transmission system effects are taken into account. WASP-IV is a powerful software product developed by the International Atomic Energy Agency (IAEA). A dynamic programming approach is used in this software to solve single-bus GEP problems [4]. In single-bus GEP problems proposed in $[1,4-6,9]$, it is assumed that total generation capacity and total system load are placed on a particular bus. Single-bus GEP problems are able to determine the total generation capacity required for the network, but unable to geographically distribute and allocate the capacities among the network buses. Consequently, the O\&M cost throughout the geographical distribution of the network is presumed to be uniform. This assumption is not practicable in real-world planning; For example, a power plant located far from a fuel resource supply center has higher fuel transmission (piping) costs in respect to closer ones. Furthermore, in single-bus GEP problems, some non-technical factors associated with the investment costs - such as the interconnection cost to the main grid and the cost of land - are uniformly distributed among the network buses. In real-world planning, such supposition reduces precision of the problem. In multi-bus GEP problems [1,7], it is supposed that the total generation requirements as well as the types and capacities of the generating units are pre-specified; here the purpose is to allocate the generation among the network buses to minimize 
generation investment costs and transmission enhancement requirements. This supposition also decreases the problem precision. All three TC-GEP variables (fuel type, capacity and place of new generation units) affect both O\&M costs and investment costs. Consequently in this paper a model is developed to solve TC-GEP problems by simultaneously computing all three of problem variables, making the problem more practical. Objective function is to minimize the total generation cost, which is composed of O\&M costs, investment costs, outage costs, transmission enhancement costs and active power loss costs. O\&M costs consist of fuel costs and non-fuel operation and maintenance costs which are depending on energy generated by each unit $[4,10]$. In this paper, a power system probabilistic production simulation (PPS) is implemented for computing the energy generated by each unit and also the expected energy not served (EENS) in each period. Invested costs consist of generation investment costs and transmission enhancement costs. Generation investment costs involve technical costs, land costs, fuel supply piping costs and the interconnection cost to the main grid. Number of power plants is effective on the most nontechnical factors of investment costs such as land costs, fuel supply piping costs and the interconnection costs to the main grid as an alternative of the unit's number. So, in this paper, investment costs are divided into two parts: fixed part costs varying with the number of power plants, and variable part costs varying with the number of plant units. In this paper, an approach is proposed for computing the number and type of power plants relative to the number and type of plant units. It is worth to note that, any of the existing lines may need to be enhanced for a higher capacity, once a generation unit is installed on a bus. Consequently in this paper to improve problem precision, transmission enhancement costs are also considered as an objective function of TC-GEP problem. Note that, in this problem the main emphasis is GEP not the actual transmission enhancement requirements. So to handle the problem complexity, it is supposed that the transmission enhancement requirements are approximately proportional to the length-based overloads [1,11]. Moreover, an AC power flow model is used to compute transmission line loading and active power losses of the transmission system. All costs are discounted to a certain reference date. Besides, salvage values for all plants and transmission equipment are considered in the objective function formulation. Capacity reserve margins, reliability indexes and fuel availability are taken into account as the TC-GEP problem constraints. In this study, a GA is used as the optimization tool for the objective function of the TC-GEP problem. A new method is used for the proposed GA in order to sustain the feasibility of candidate solutions through the GA's operators. Four different types of plant units - natural gas, coal, oil and nuclear- are considered as candidate units for TC-GEP problem. To numerically evaluate the efficiency of the proposed method, simulation results on the 4-bus test system from Grainger \& Stevenson for a planning horizon of one year and the IEEE-RTS 24-bus test system for a planning horizon of three years with growing complexity containing 16 and 288 decision variables, respectively, are used. EM is also applied to solve the TC-GEP problem for the Grainger \& Stevenson 4-bus test system for a planning horizon of one year; the results of the GA are compared and validated against the EM. The results indicated that the GA is an effective alternative for the solution of the proposed TC-GEP problem.

\section{Problem Formulation}

In this section, a reconfigured formulation of the TCGEP problem is presented. The problem is to specify the place, type and capacity of each unit required in each year of the study period from a list of available options. In doing so, besides satisfying different constraints such as meeting load demand, the present value of the total costs incurred should be minimized. The TC-GEP problem is dynamic and it is supposed that the forecasted load will be specified for each stage. The objective function terms as well as the different constraints are presented in the following subsections.

\subsection{Capital investment Costs}

The capital investment costs along the planning horizon consists of generation investment costs and transmission enhancement costs as:

$$
\overline{I_{t}}=\overline{I G}_{t}+\overline{I T}_{t}^{\text {worst }}
$$

At the following subsections, formulation of generation investment and transmission enhancement costs are discussed.

\section{A. Generation Capital Investment Costs}

Generation investment costs in each year can be computed as:

$$
I G_{t}=\sum_{b=1}^{N_{b}}\left[\begin{array}{l}
\sum_{p=1}^{N_{p}}\left(X_{p, b} \times C I G F_{p, b}\right)+ \\
\sum_{k=1}^{N_{k}}\left(Y_{k, b} \times C I G V_{k, b} \times P G^{k}\right)
\end{array}\right]
$$

In Formula (2), $X_{p, b}$ is the number of type-p power plants placed on bus $b ; C I G F_{p, b}$ denotes the fixed portion of the generation capital investment cost which is dependent on the number of power plants. $C I G F_{p, b}$ can be determined as: 


$$
\begin{aligned}
& C I G F_{p, b}=C I G F T_{p, b}+C I G F L_{p, b}+C I G F P_{p, b}+ \\
& C I G F G C_{p, b}
\end{aligned}
$$

The terms in formula (3) refer to parts of $C I G F_{p, b}$ which are concerning to technical, land, fuel piping costs and costs of interconnection into the main grid, respectively. Power plants composed of distributed units on network buses follow these rules:

Gas, steam and nuclear units placed on a bus where there is no other unit of the same type make up a new power plant.

Two gas units with a steam unit make up a combined-cycle power plant.

Maximum total capacity of each power plant is considered to be equal to $1,300 \mathrm{MW}$.

In formula (2), $Y_{k, b}$ denotes the number of type-k units placed on bus $b ; C I G V_{k, b}$ is the part of generation capital investment costs which is variable with the number of units. $C I G V_{k, b}$ can be calculated from formu la (4).

$$
\begin{aligned}
& C I G V_{k, b}=C I G V T_{k, b}+C I G V L_{k, b}+C I G V P_{k, b}+ \\
& C I G V G C_{k, b}
\end{aligned}
$$

The terms in (4) refer to parts of $C I G V_{k, b}$ which are concerning to technical, land, fuel piping costs and costs of interconnection into the main grid, respectively.

\section{B. Transmission Enhancement Costs}

As aforementioned, transmission enhancement requirements are considered proportional to the lengthbased overloads and are determined for a period of one year under the worst conditions (i.e., a period with the minimu m reserve capacity). It is worthwhile to note that the transmission system model proposed in this paper is approximated and is not the only way to observe this point. The investment cost of transmission en hancement requirements is obtained from formula (5);

$$
I T_{t}^{\text {worst }}=\sum_{j=1}^{N L}\left(Z_{j} \times\left(S L_{j}-S R_{j}\right) \times C I T_{j}\right)
$$

Where $C I T_{j}$ is the investment cost (\$/MVA) of line $j$ that requires to be enhanced; $S L_{j}$ denotes power flow (MVA) through transmission line $j$ under the worst conditions; $Z_{j}$ is set to 1 only if line $j$ is overloaded, otherwise $Z_{j}$ is set to zero; Two objective functions generation investment costs and transmission enhancement costs have conflicts in distributing units among the buses. Increasing the number of power plants throughout distributing units among the network buses will increase the generation investment costs, whereas the transmission enhancement costs will be reduced by decreasing length-based overloads.

\subsection{O\&M Costs of Generation}

O\&M costs in each year consist of fuel costs and non-fuel $O \& M$ costs of generation. O\&M costs can be calculated as:

$$
M_{t}=\sum_{f=1}^{N_{\text {prt }}} \sum_{b=1}^{N_{b}} \sum_{k=1}^{N_{k}}\left(\sum_{i=1}^{m_{k, b, f}}\left[\begin{array}{l}
\left(H R G_{k}^{\mathrm{min}} \times E G_{i}^{\text {base }}+\right. \\
\left.H R G_{k}^{\mathrm{max}} \times E G_{i}^{\text {peak }}\right) \times C F G_{k, b} \\
+\operatorname{Com}_{k, b}^{\mathrm{var}} \times E G_{i}^{\text {tot }} \\
+\operatorname{Com}_{k, b}^{f i x} \times P G^{k}
\end{array}\right]\right)
$$

where $m_{k, b, h}$ denotes the total number of type-k plant units placed on bus $b$, in period $f$ of year $t$ of the study period. $E G_{i}^{\text {base }}, E G_{i}^{\text {peak }}$ and $E G_{i}^{\text {tot }}$ are the energy generated in base and peak capacity, and total energy generated by the type-k $i^{\text {th }}$ plant unit located at bus $b$, in period $f$ of year $t$ of the study period, respectively. In this paper, PPS is used for power system generation expansion planning as well as laying seas onal operation plans for existing power systems. Doing so, the PPS not only calculates the output of every generating unit and performs cost analysis from the perspective of optimization, but also provides important data for dealing with different problems arising during operation. The equivalent load duration curve (ELDC) is the most important concept confirmed in the development of PPS technology. It ingeniously integrates a generating unit's random outage with the random load model and is the core of PPS [12]. Indices of ${ }^{b a s e} E G_{i}^{k, b, f, t}$, ${ }^{p e a k} E G_{i}{ }^{k, b, f, l}$ and ${ }^{\text {tot }} E G_{i}{ }^{k, b, f, t}$ are computed using an ELDC for the PPS. Formula (7) shows the equation of the ELDC used for fixed and candidate units:

$$
f^{(i)}(x)=p_{i} f^{(i-1)}(x)+q_{i} f^{(i-1)}\left(x-c_{i}\right)
$$

Where $P_{i}$ is the operation rate of generating unit $i$ and $q_{i}=1-p_{i}$ indicates the unit's Forced Outage Rate (FOR); $c_{i}$ is generating capacity for unit $i$ in $p . u$; energy generated by each unit is calculated by formula (8)

$$
E_{g i}=T p_{i} \int_{x_{i-1}}^{x_{i}} f^{(i-1)}(x) d x
$$

Where $x_{i}$ is equal to $\sum_{j=1}^{i} C_{j}$. 


\subsection{Outage Cost}

FOR of a generating unit represents the percentage of time the unit maybe unavailable due to unexpected outages. A generating unit maybe tripped at a rate given by it's FOR. Some portion of the energy demand cannot be served owing to the FORs of the units and based on demand and available reserves. EENS is computed from formula (9) and cannot be equal to 0 ; rather, it should be minimized as a cost term called outage cost, specified by formula (10):

$$
\begin{gathered}
\text { EENS }=T \int_{C_{t}}^{x_{\text {max }}+C_{t}} f^{(n)}(x) d x \\
O_{t}=\left[\begin{array}{l}
a+b \times\left(\sum_{f=1}^{N_{p e r}} E^{\prime} E N S^{f}\right) \\
+C \times\left(\sum_{f=1}^{N_{p e r}} E^{f} S^{f}\right)^{2}
\end{array}\right]
\end{gathered}
$$

Where $E E N S^{f, t}$ denotes EENS (MWH) in period $f$, and year $t$ of the study period; $c_{t}$ is the total capacity of all of the active generating units during the time interval; $a, b$ and $c$ are constants; and ELDC of the PPS is also used to calculate EENS and loss of load probability(LOLP) used in the constraint objective[12]. LOLP can be calculated from formula (11).

$$
L O L P=f^{(n)}\left(C_{t}\right)
$$

\subsection{Transmission Losses Costs}

The costs of active power losses can be calculated as:

$$
L_{t}=\left[C L T \times \sum_{j=1}^{N L}\left(R L_{j} \times\left(I L_{j}\right)^{2}\right)\right]
$$

Where $I L_{j}$ denotes the current of line $j$ which is calculated by solving the AC load flow for the system involving candidate units. As aforementioned, in this model, it is assumed that the network load is uniformly increased between the network load buses according to the forecasting load for each year.

\subsection{Objective Function of the Proposed Method}

As aforementioned, the discounted value of the total generating costs is considered as the objective function, which is represented by formula (13):

$$
\operatorname{Min} C=\sum_{t=1}^{T}\left[\overline{I_{t}}+\overline{M_{t}}+\overline{O_{t}}+\overline{L_{t}}-\overline{S_{t}}\right]
$$

Where the first and second terms refer to presentworth values of capital investment costs and O\&M costs, respectively. In addition, the third and fourth terms represent the present-worth value of outage costs and power active loss costs, respectively. $\overline{S_{t}}$ is the salvage value of the investment costs, which is deducted from the capital investment costs. In order to calculate the present-worth value of the cost components of formula (13), it is supposed that the full capital investment for a plant or a transmission equipment added by the expansion plan are made at the beginning of the year in which it goes into the service. As a matter of fact, the present-worth factors are specified with this as sumption.

\subsection{Constraints of the Proposed Method}

Two types of constraints are considered in the proposed TC-GEP problem: fuel constraints and technical constraints.

\section{A. Fuel Constraints}

As can be seen from formula (14), each fuel supply center is able to supply a maximum amount of generation capacity.

$$
\begin{aligned}
& F U V_{m, t}^{e x}+\sum_{i=1}^{N U_{t}}\left(F U V_{m, i} \times E G_{i, t}^{\text {tot }} \times U_{i, t}\right) \leq F U V_{m, t}^{\max } \\
& \forall m=1, \ldots, N_{f u}, t=1, \ldots, T
\end{aligned}
$$

\section{B. Technical Constraints}

There are uncertainties that may cause generation units to trip unexpectedly at any time. Consequently generation capacity should be adequate in satisfying the load requirements. The following two constraints, then, should be taken into account:

$$
\begin{aligned}
& \left(1+a_{t}\right) D_{t, c} \geq P\left(K_{t, c}\right) \geq\left(1+b_{t}\right) D_{t, c} \\
& \forall t=1, \ldots, T \\
& L O L P_{t} \leq L O L P_{\max } \\
& \forall t=1, \ldots, T
\end{aligned}
$$

Where $c$ is the critical period. It denots the period of the year in which the difference between the relevant available generating capacity and the peak demand has the smallest value. Formu la (15) clearly implies that the installed capacity in the critical period must lie between the given maximum and minimum reserve margins $-a_{t}$ and $b_{t}$, respectively-above the peak demand $\left(D_{t, c}\right)$ during the critical period of the year. 
In the proposed TC-GEP problem, the reliability of the system is computed in terms of the LOLP index for each period of the year, as in formula (16). The LOLP of each period is specified as the average annual LOLP, where the sum of the LOLP of the periods is divided by the total number of periods.

\section{Solution Methodology}

As previously mentioned, the purpose of this problem was to find the optimum number, type and location of the candidate generating units. The objectives are described in Section 2.In the following section, a GA is employed to the proposed method.

\subsection{Applying a GA to the Proposed Method}

In nature, each species must adapt itself for the maximum likelihood of survival in a challenging environment. Species with improved characteristics tend to survive overtime. In fact, species with higher fitness levels survive longer. This type of phenomenon, which occurs in nature, is the basis for the evolutionarybased GA [1,13-15].To solve a TC-GEP problem using a GA problem, variables are combined and represented as mixed integer coding in each chromosome. The data structure of the chromosome can be depicted, as shown in Figure 1. As can be seen from this figure, each three genes of the chromosome refer to the number of type-k plants on bus $b$, in year $t$ of the study period. In the proposed GA, candidate solutions of the initial population are randomly selected between all solutions to satisfy the constraints in formula (15), and new solutions are obtained through the GA's operators (selection, crossover, and mutation) which are checked to sustain feasibility.

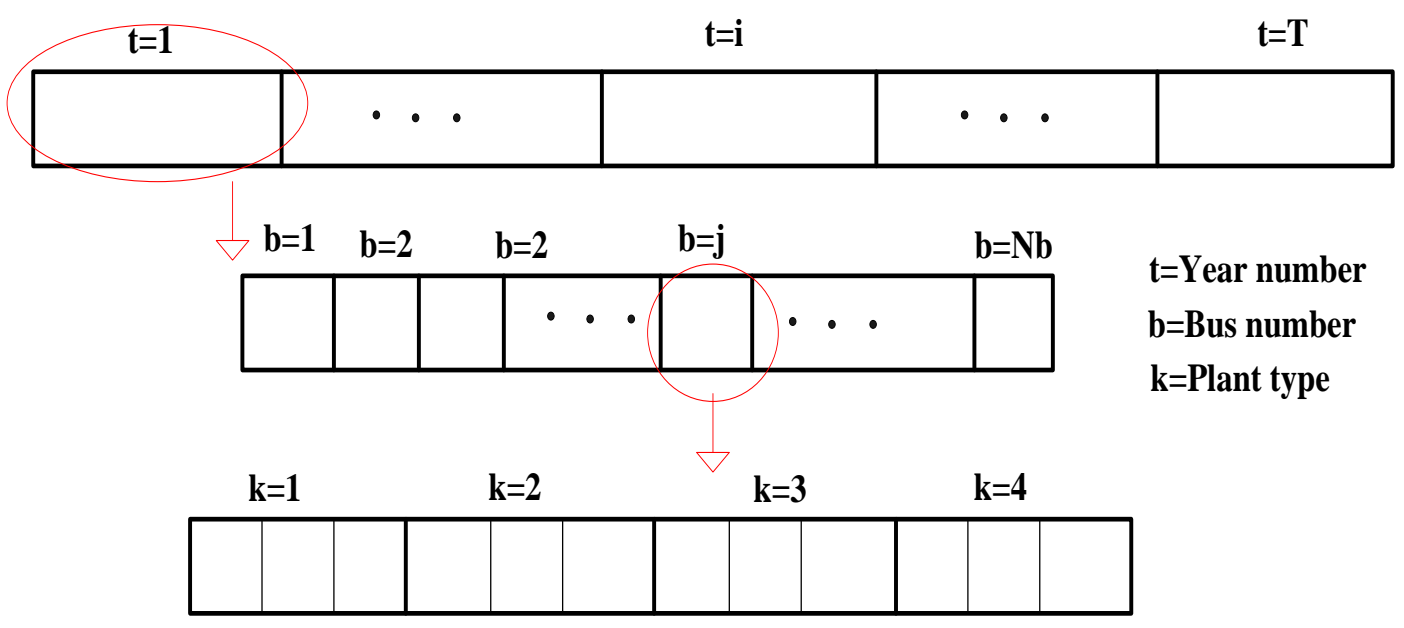

Fig. 1: Data structure of each chromosome of GA

\section{Sinulation}

In order to demonstrate the effectiveness of the proposed approach, it is applied to the 4-bus test system from Grainger \& Stevenson for a planning horizon of one year and an IEEE-RTS 24-bus test system for a planning horizon of three years with growing complexity. For these case studies, chromosomes containing 48 and 864 genes, respectively, are considered (see Figure 1). In this study, candidate plants for generation expansion planning are selected from four different types of natural gas units, coal units, oil units and nuclear units. Two case studies and their results are presented in the following subsections.

\subsection{Case Study 1}

In this first case, the problem is applied to a 4-bus, 1generator case from Grainger \& Stevenson [16]. The figure of this system is presented in Figure 2.

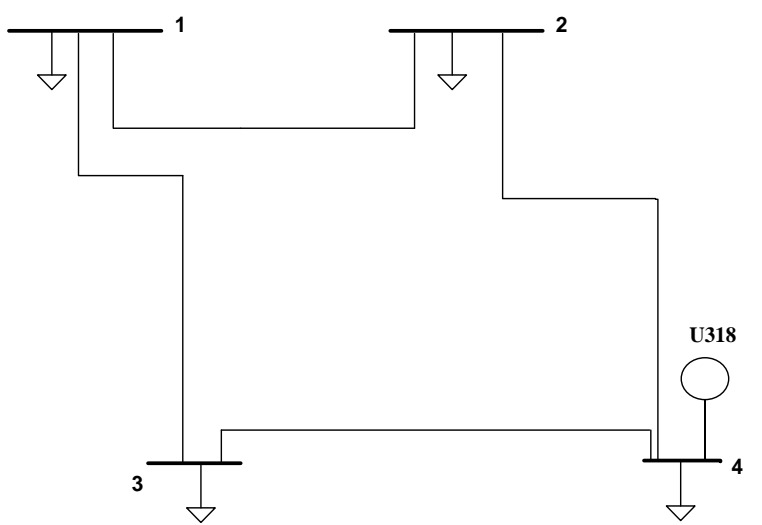

Fig. 2: Case study 1: 4 bus test system from Grainger \& Stevenson

As can be seen from this figure, there is only one fixed nuclear unit of $318 \mathrm{MW}$ nominal capacity, and $8 \%$ FOR, which is placed on bus 4 ; total network load is $500 \mathrm{MW}$. For this case study, the TC-GEP problem is solved for a planning horizon of one year. First, a GA is 
used as the optimization tool, then the Enumeration Method (EM) is used to solve the problem for all feasible chromosomes, satisfying formula (15).

It is noteworthy that the proposed expansion plans by the GA and EM are the same. The total objective function is evaluated for this case study, as described in Section 2. A PPS is also employed for calculating the energy generated by each unit and also the expected energy not served in each period for this case study; Figure 3 shows the ELDC of the PPS for the proposed expansion plan by the GA for case study 1 . As can be seen, the ELDC is evaluated for six fixed and candidate units with respect to their FORs. The proposed expansion plan for case study 1, generated energy and O\&M costs of generation of each unit during the first period for this expansion plan is presented in Table 1 .
As can be seen, the candidate plants are distributed on buses 1 and 3. Capital investment costs related to various factors (technical, land, fuel piping and interconnection to the main grid) of the candidate units for the expansion plan proposed for Case study 1 are presented in Table 2. As can be seen from this table, two steam and natural-gas power plants are developed by distributing candidate units between buses 1 and 3 . Also, the expected energy not served, overload, active power losses and the discounted value of all of the cost terms of the objective function for the proposed expansion plan for case study 1 are presented in Table 3 . Total objective function for case study 1 is equal to $\$ 1,059,931,580$. The GA converges at the $4^{\text {th }}$ iteration.

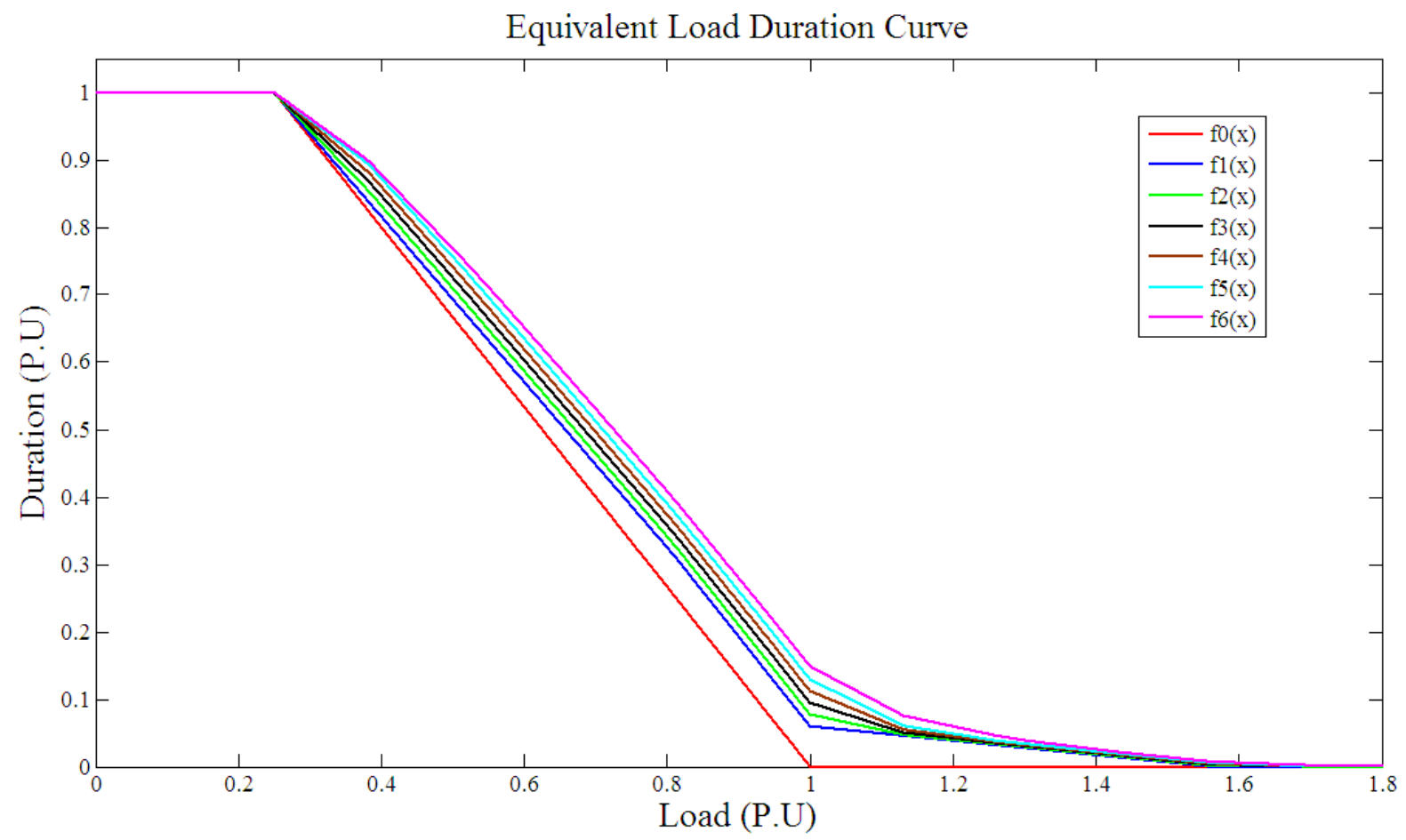

Fig. 3: ELDC for case study 1

Table 1: Generated Energy and O\&M costs of generation of each unit during first period for proposed expansion plan by GA for Case study 1

\begin{tabular}{|c|c|c|c|c|c|c|c|c|}
\hline $\begin{array}{c}\text { Unit } \\
\text { number }\end{array}$ & $\begin{array}{l}\text { Unit } \\
\text { type }\end{array}$ & $\begin{array}{c}\text { Bus } \\
\text { Number }\end{array}$ & $\begin{array}{l}\text { Unit } \\
\text { Type }\end{array}$ & $\begin{array}{c}\text { Total } \\
\text { Generated } \\
\text { Energy } \\
(\text { GWH) }\end{array}$ & $\begin{array}{c}\text { Generated } \\
\text { Energy } \\
\text { in base Capacity } \\
(\text { GWH) }\end{array}$ & $\begin{array}{c}\text { Fuel costs } \\
(\mathbf{K} \$)\end{array}$ & $\begin{array}{l}\text { Non-fuel } \\
\text { O\&M } \\
\text { costs }(\mathbf{K} \$)\end{array}$ & $\begin{array}{c}\text { O\&M cost } \\
\text { involving } \\
\text { fuel costs }(K \$)\end{array}$ \\
\hline 1 & Fixed & 4 & U318 & 567.95 & 181.33 & 7951.35 & 737.63 & 8688.99 \\
\hline 2 & Candidate & 3 & F-CC & 79.96 & 40.28 & \multirow{2}{*}{1193.65} & \multirow{2}{*}{246.41} & \multirow{2}{*}{1440.07} \\
\hline 3 & Candidate & 3 & F-CC & 58.46 & 36.2 & & & \\
\hline 4 & Candidate & 1 & FOIL & 35.96 & 32.11 & \multirow{4}{*}{6925.83} & \multirow{4}{*}{1657.07} & \multirow{4}{*}{8582.9} \\
\hline 5 & Candidate & 1 & FOIL & 16.4 & 4.1 & & & \\
\hline 6 & Candidate & 1 & FOIL & 16.24 & 10.43 & & & \\
\hline 7 & Candidate & 1 & FOIL & 4.04 & 1.01 & & & \\
\hline Total & - & - & - & 779.01 & 305.46 & 16070.83 & 2641.11 & 18711.96 \\
\hline
\end{tabular}


Table 2: Capital investment costs for Case study 1

\begin{tabular}{|c|c|c|c|c|c|c|c|c|c|c|c|c|c|}
\hline \multirow{2}{*}{$\begin{array}{c}\text { Terms/ } \\
\text { Power } \\
\text { Plant } \\
\text { Num- } \\
\text { ber }\end{array}$} & \multirow{2}{*}{$\begin{array}{c}\text { Power } \\
\text { Plant } \\
\text { type }\end{array}$} & \multirow{2}{*}{$\begin{array}{c}\text { Bus } \\
\text { Num- } \\
\text { ber }\end{array}$} & \multirow{2}{*}{$\begin{array}{l}\text { Unit } \\
\text { Num- } \\
\text { ber }\end{array}$} & \multicolumn{2}{|c|}{$\begin{array}{l}\text { Technical } \\
\text { costs }(\mathbf{K} \$)\end{array}$} & \multicolumn{2}{|c|}{$\begin{array}{c}\text { Land } \\
\text { costs }(K \$)\end{array}$} & \multicolumn{2}{|c|}{$\begin{array}{l}\text { Fuel piping } \\
\text { costs }(K \$)\end{array}$} & \multicolumn{2}{|c|}{$\begin{array}{l}\text { Costs of interconnection } \\
\text { to the main grid }(K \$)\end{array}$} & \multirow{2}{*}{$\begin{array}{l}\text { Fixed } \\
\text { costs } \\
(\mathbf{K} \$)\end{array}$} & \multirow{2}{*}{$\begin{array}{c}\text { Investment } \\
\text { Costs } \\
(\mathrm{K} \$)\end{array}$} \\
\hline & & & & $\begin{array}{l}\text { Depre- } \\
\text { ciable }\end{array}$ & $\begin{array}{l}\text { Non- } \\
\text { depre- } \\
\text { ciable }\end{array}$ & $\begin{array}{l}\text { Depre- } \\
\text { ciable }\end{array}$ & $\begin{array}{l}\text { Non- } \\
\text { depre- } \\
\text { ciable }\end{array}$ & $\begin{array}{l}\text { Depre- } \\
\text { ciable }\end{array}$ & $\begin{array}{l}\text { Non- } \\
\text { depre- } \\
\text { ciable }\end{array}$ & $\begin{array}{c}\text { Depre- } \\
\text { ciable }\end{array}$ & $\begin{array}{l}\text { Non-depre- } \\
\text { ciable }\end{array}$ & & \\
\hline \multirow{2}{*}{1} & \multirow{2}{*}{ NGAS } & \multirow{2}{*}{3} & 2 & 893.6 & 0 & 80 & 0 & 135 & 0 & 82 & 0 & \multirow{2}{*}{150781.82} & \multirow{2}{*}{153163.02} \\
\hline & & & 3 & 893.6 & 0 & 80 & 0 & 135 & 0 & 82 & 0 & & \\
\hline \multirow{4}{*}{2} & \multirow{4}{*}{ STEAM } & \multirow{4}{*}{1} & 4 & 2960.4 & 148 & 310 & 155 & 15.27 & 7.63 & 35 & 0 & \multirow{4}{*}{103818.18} & \multirow{4}{*}{118343.38} \\
\hline & & & 5 & 2960.4 & 148 & 310 & 155 & 15.27 & 7.63 & 35 & 0 & & \\
\hline & & & 6 & 2960.4 & 148 & 310 & 155 & 15.27 & 7.63 & 35 & 0 & & \\
\hline & & & 7 & 2960.4 & 148 & 310 & 155 & 15.27 & 7.63 & 35 & 0 & & \\
\hline \multicolumn{3}{|c|}{ Total } & & 13628.8 & 592 & 1400 & 620 & 331.08 & 30.52 & 304 & 0 & 254600 & 271506.3 \\
\hline
\end{tabular}

Table 3: Value of all cost terms of objective function for the expansion plan proposed by GA for Case studies 1 and 2

\begin{tabular}{|c|c|c|c|c|c|c|c|c|c|c|c|}
\hline $\begin{array}{l}\text { Terms/ } \\
\text { Expansion } \\
\text { plan } \\
\text { proposed } \\
\text { by GA }\end{array}$ & $\begin{array}{c}\text { Year } \\
\text { number }\end{array}$ & $\begin{array}{c}\text { Expected } \\
\text { energy } \\
\text { not served } \\
(\mathbf{G W H})\end{array}$ & $\begin{array}{c}\text { Overload } \\
\text { (MVA) }\end{array}$ & $\begin{array}{l}\text { Active } \\
\text { power } \\
\text { losses } \\
\text { (MW) }\end{array}$ & $\begin{array}{c}\text { O\&M } \\
\text { cost } \\
(\mathbf{K} \$)\end{array}$ & $\begin{array}{c}\text { Capital } \\
\text { investment } \\
\text { cost }(K \$)\end{array}$ & $\begin{array}{c}\text { Salvage } \\
\text { value of } \\
\text { capital } \\
\text { investment } \\
\text { cost }(K \$)\end{array}$ & $\begin{array}{c}\text { Outage } \\
\text { cost }(\mathbf{K} \$)\end{array}$ & $\begin{array}{c}\text { Transmission } \\
\text { enhancement } \\
\text { cost }(K \$)\end{array}$ & $\begin{array}{l}\text { Active } \\
\text { power } \\
\text { losses } \\
\text { cost }(\mathbf{K} \$)\end{array}$ & $\begin{array}{c}\text { Objective } \\
\text { function } \\
(\mathbf{K} \$)\end{array}$ \\
\hline $\begin{array}{c}\text { Case } \\
\text { study1 }\end{array}$ & 1 & 3.217 & 74.943 & 5.81317 & 69561.669 & 1621617.09 & 1403320.0396 & 64710098 & 123460.24 & 1511.63 & 1059931.58 \\
\hline \multirow{4}{*}{$\begin{array}{c}\text { Case } \\
\text { study } 2\end{array}$} & 1 & 0.318438 & 13.472128 & 54.7463 & 288180.33 & 860016.872 & 604981.32 & 43801.159 & 14618.101 & 14235.99 & 615871.127 \\
\hline & 2 & 0.096564 & 411.6279 & 131.461 & 348381.41 & 1044793.611 & 801774.432 & 11660.672 & 415628.523 & 31077.014 & 1049766.803 \\
\hline & 3 & 0.08349 & 682.3472 & 258.482 & 334248.126 & 601305.334 & 531660.627 & 9147.969 & 827778.368 & 55549.241 & 12963684412 \\
\hline & Total & 0.4984 & 1107.44 & 444.689 & 970809.871 & 2506115.818 & 1938416.387 & 64609.801 & 1258024.993 & 100862246 & 2962006343 \\
\hline
\end{tabular}

\subsection{Case Study 2}

An IEEE-RTS 24-bus test system is selected as the second case study to which the TC-GEP problem is applied for a planning horizon of three years with growing complexity [17-18]. Figure 4 shows this test system. As can be seen from this figure, there are 32 fixed units of $3,405 \mathrm{MW}$ total nominal generating capacity. Total network load is $2,850 \mathrm{MW}$, and it is assumed that the network load would uniformly increased between the network load buses.

The proposed GA that is validated for case study 1 and compared with the EM is also employed to solve the TC-GEP problem for this case study. The expansion plan suggested by the GA for case study 2 is shown in Table 4 . As can be seen, 8 power plants consisting of 18 units each are distributed between buses 7,11, 12 and 17.

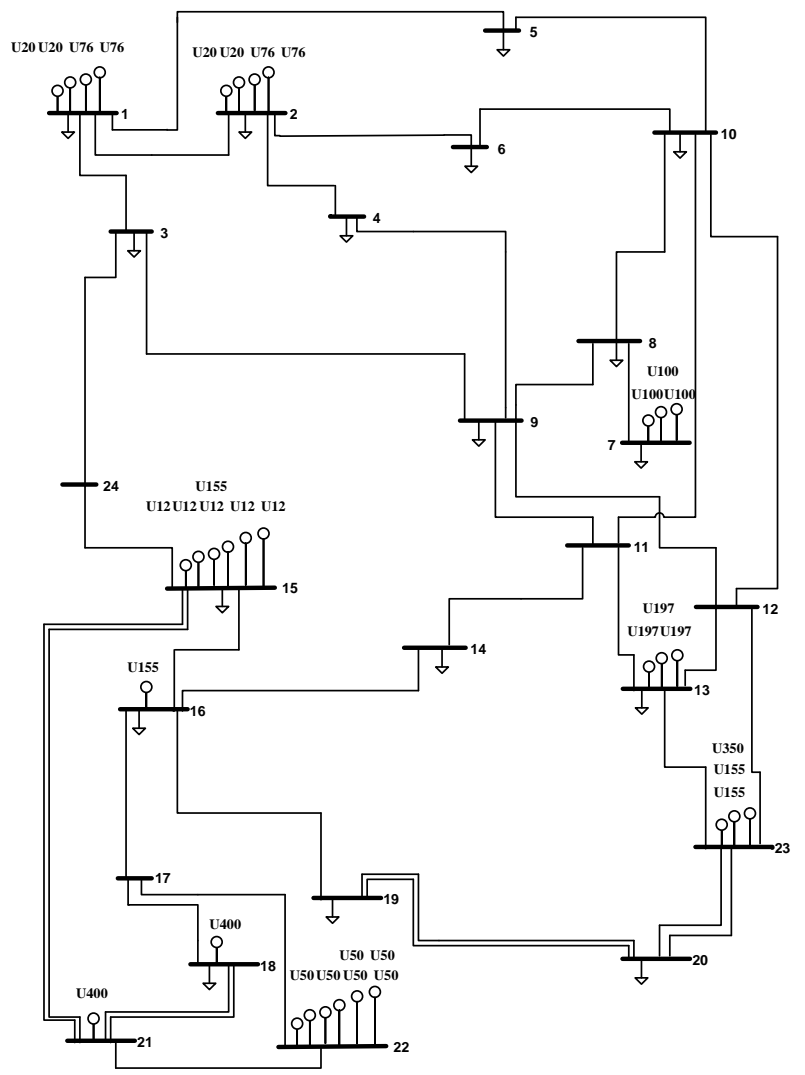

Fig. 4: Case study 2: IEEE-RTS 24-bus test system 
Table 4: Specification of expansion plan proposed by GA for Case st udy 2

\begin{tabular}{|c|c|c|c|c|c|c|}
\hline $\begin{array}{c}\text { Year } \\
\text { number }\end{array}$ & $\begin{array}{c}\text { Power plant } \\
\text { number }\end{array}$ & $\begin{array}{c}\text { Power plant } \\
\text { type }\end{array}$ & $\begin{array}{l}\text { Power plant } \\
\text { capacity }\end{array}$ & Bus number & Unit number & Unit type \\
\hline \multirow{5}{*}{1} & 1 & STEAM & 280 & 11 & 1 & FCOA \\
\hline & 2 & NGAS & 174 & 11 & 2 & F-CC \\
\hline & \multirow{3}{*}{3} & \multirow{3}{*}{ CCYC } & \multirow{3}{*}{628} & \multirow{3}{*}{12} & 3 & F-CC \\
\hline & & & & & 4 & F-CC \\
\hline & & & & & 5 & FCOA \\
\hline \multirow{7}{*}{2} & \multirow{2}{*}{4} & \multirow{2}{*}{$\mathrm{CCYC}$} & \multirow{2}{*}{454} & \multirow{2}{*}{7} & 6 & F-CC \\
\hline & & & & & 7 & FOIL \\
\hline & 2 & NGAS & 348 & 11 & 8 & $\mathrm{~F}-\mathrm{CC}$ \\
\hline & \multirow{2}{*}{3} & \multirow{2}{*}{ CCYC } & \multirow{2}{*}{983} & \multirow{2}{*}{12} & 9 & FOIL \\
\hline & & & & & 10 & FCOA \\
\hline & 5 & NGAS & 174 & 17 & 11 & F-CC \\
\hline & 6 & NUCL & 400 & 17 & 12 & NUCL \\
\hline \multirow{6}{*}{3} & 4 & $\mathrm{CCYC}$ & 529 & 7 & 13 & FOIL \\
\hline & \multirow{2}{*}{7} & \multirow{2}{*}{ STEAM } & \multirow{2}{*}{355} & \multirow{2}{*}{7} & 14 & FOIL \\
\hline & & & & & 15 & FCOA \\
\hline & 1 & STEAM & 355 & 11 & 16 & FOIL \\
\hline & 3 & CCYC & 1263 & 12 & 17 & FCOA \\
\hline & 8 & STEAM & 35 & 17 & 18 & FOIL \\
\hline
\end{tabular}

Four of these power plants are of the steam type, three are natural-gas power plants, one is nuclear and five are combined-cycle power plants. Five of the candidate units are entered into the network during the first year of the study period, seven of them are entered during the second year and six are entered during the third year of the study period. Fuel and non-fuel O\&M costs and capital investment costs related to various factors (e.g., technical, land, fuel piping and interconnection to the main grid) of the candidate units for the expansion plan proposed by the GA for case study 2 are presented in Table 5. All terms are computed for each year of the study period separately. Also, the expected energy not served, overload, active power losses and the discounted value of all of the cost terms of objective function for each year of the study period of the proposed expansion plan for case study 2 are presented in Table 3 . The total objective function for case study 2 is equal to $\$ 2,962,006,343$. The GA convergence for case study 2 is shown in Figure 5. As can be seen, the GA converges at the $32^{\text {th }}$ iteration.

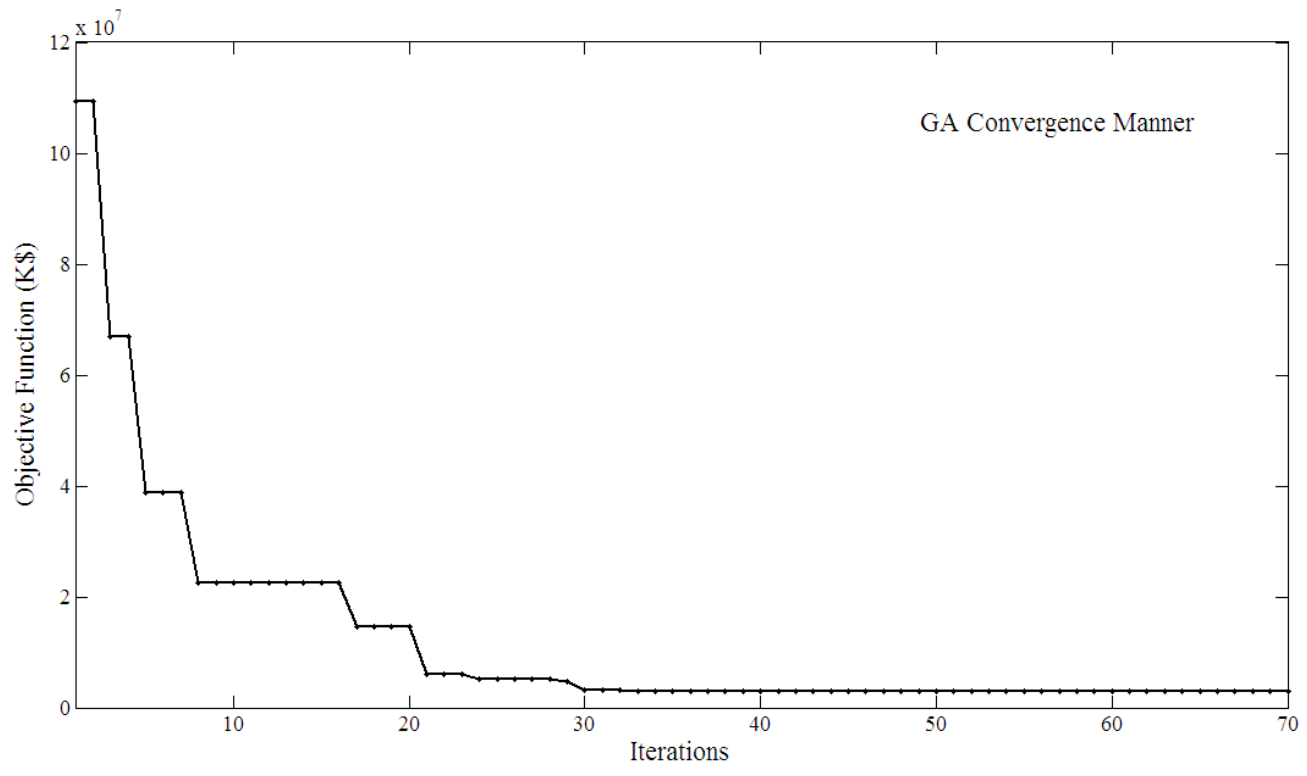

Fig. 5: GA convergence manner for Case study 2 
Table 5: O\&M capital investment costs of candidate units for the expansion plan proposed by GA for Case study 2

\begin{tabular}{|c|c|c|c|c|c|c|c|c|c|c|c|c|c|}
\hline \multirow{2}{*}{$\begin{array}{l}\text { Terms/Year } \\
\text { number }\end{array}$} & \multirow{2}{*}{$\begin{array}{l}\text { Fuel costs } \\
(\mathbf{K} \$)\end{array}$} & \multirow{2}{*}{$\begin{array}{l}\text { Non-fuel } \\
\text { O\&M } \\
\text { costs } \\
\text { (K\$) }\end{array}$} & \multirow{2}{*}{$\begin{array}{l}\text { O\&M cost } \\
\text { involving } \\
\text { fuel costs } \\
\text { (K\$) }\end{array}$} & \multicolumn{2}{|c|}{$\begin{array}{l}\text { Technical } \\
\text { costs }(\mathbf{K})\end{array}$} & \multicolumn{2}{|c|}{$\begin{array}{c}\text { Land } \\
\text { costs (K\$) }\end{array}$} & \multicolumn{2}{|c|}{$\begin{array}{l}\text { Fuel piping } \\
\text { costs (K\$) }\end{array}$} & \multicolumn{2}{|c|}{$\begin{array}{l}\text { Costs of } \\
\text { interconnection to } \\
\text { the main grid (K\$) }\end{array}$} & \multirow{2}{*}{$\begin{array}{l}\text { Fixed } \\
\text { costs } \\
(\mathbf{K} \$)\end{array}$} & \multirow{2}{*}{$\begin{array}{l}\text { Investment } \\
\text { costs (K\$) }\end{array}$} \\
\hline & & & & $\begin{array}{l}\text { Depre- } \\
\text { ciable }\end{array}$ & $\begin{array}{c}\text { Non- } \\
\text { depreciable }\end{array}$ & Depreciable & $\begin{array}{l}\text { Non- } \\
\text { depre- } \\
\text { ciable }\end{array}$ & $\begin{array}{l}\text { Depre- } \\
\text { ciable }\end{array}$ & $\begin{array}{c}\text { Non- } \\
\text { depreciable }\end{array}$ & $\begin{array}{l}\text { Depre- } \\
\text { ciable }\end{array}$ & $\begin{array}{c}\text { Non- } \\
\text { depreciable }\end{array}$ & & \\
\hline 1 & 285685.879 & 46784.809 & 332470.688 & 240689.76 & 16119.6 & 24948 & 14870.8 & 20745.2 & 9872.8 & 7364.4 & 0 & 611408 & 946018.56 \\
\hline 2 & 381485.183 & 60784.4587 & 442269.642 & 539880.75 & 9971.9 & 34936 & 9318.95 & 16581.725 & 5179.725 & 6856.9 & 0 & 682000 & 130472595 \\
\hline 3 & 390233.168 & 76499.263 & 466732.432 & 280092.5 & 20461.9 & 23010 & 17178.15 & 12089.125 & 10003.725 & 4002 & 0 & 433500 & 800337.4 \\
\hline \multirow{2}{*}{ Total } & \multirow{2}{*}{1057404.23} & \multirow{2}{*}{184068.53} & \multirow{2}{*}{1241472.762} & 1060663.01 & 46553.4 & 82894 & 41367.9 & 49416.05 & 25056.25 & 182233 & 0 & \multirow{2}{*}{1726908} & \multirow{2}{*}{305108191} \\
\hline & & & & \multicolumn{2}{|c|}{1107216.41} & \multicolumn{2}{|c|}{124261.9} & \multicolumn{2}{|c|}{74472.3} & \multicolumn{2}{|c|}{18223.3} & & \\
\hline
\end{tabular}

\section{Conclusions}

Usually, in order to solve GEP problems, the expansion problem is divided into two sub-problems. The first is a single-bus GEP in which the transmission system is ignored, and the next is a multi-bus GEP in which trans mission system effects are considered. This classification is not practicable in real-world planning. In order, then, to make TC-GEP problems more practicable, the study presented here is developed in order to solve such problems by simultaneously determining the location, type and capacity of each unit needed in each year of the study period. The objective function is used to minimize total generation costs which are composed of O\&M costs, investment costs, outage costs, trans mission enhancement costs and active power loss costs. Power system PPS is used to calculate the energy generated by each unit and also the expected energy not served in each period. The 4-bus test system from Grainger \& Stevenson and the IEEE-RTS 24-bus test system are used as test systems to numerically evaluate the efficiency of the proposed method. Simulation results are provided for the test systems for a planning horizon of one year and a planning horizon of three years with growing complexity, respectively. The results of the GA are compared and validated against the EM in solving the TC-GEP problem for the Grainger \& Stevenson 4-bus test system. The results indicate that the GA is an effective alternative to the solution of the proposed TC-GEP problem.

\section{Acknowledgments}

The authors would like to thank the anonymous reviewers for their careful reading of this paper and for their helpful comments. It is a great pleasure to thank the manager and staff of Ansar Islamic Center for their helping in providing a good office for doing this research.

\section{References}

[1] Hossein Seifi, Mohammad Sadegh Sepasian, "Electric Power System Planning, Issues, Algorithms and Solutions", Springer-Verlag Berlin Heidelberg, ISSN 1612-1287, 2011,.
[2] Jose L. Ceciliano Meza, Mehmet Bayram Yildirim, and Abu S. M. Masud,“A Multiobjective Evolutionary Programming Algorithm and Its Applications to Power Generation Expansion Planning" IEEE Trans. Syst., Man, Cybern. A, Syst. „Humans, VOL.39, NO.5, SEPTEMBER 2009;

[3] Jose L. Ceciliano Meza, Mehmet Bayram Yildirim, and Abu S. M. Masud, "A Model for the Multiperiod Multiobjective Power Generation Expansion Problem", IEEE Trans. Power. Syst., VOL.22, NO.2, MAY 2007;

[4] "Introduction to the WASP IV Model, User's Manual", International Atomic Energy Agency, Vienna, Austria, Nov. 2001.

[5] S. Kannan, S. Baskar, James D. McCalley and P. Murugan, "Application of NSGA-II Algorithm to Generation Expansion Planning ", IEEE Trans. Power. Syst., VOL. 24, NO. 1, FEBRUARY 2009;

[6] S. Kannan, S. Mary Raja Slochanal, and Narayana Prasad Padhy, "Application and Comparison of Metaheuristic Techniques to Generation Expansion Planning Problem", IEEE Trans. Power. Syst., VOL. 20, NO. 1, FEBRUARY 2005

[7] Mohammad Sadegh Sepasian, Hossein Seifi, Asghar Akbari Foroud, and A. R. Hatami, "A Multiyear Security Constrained Hybrid Generation-Transmission Expansion Planning Algorithm Including Fuel Supply Costs", IEEE Trans. Power. Syst., VOL. 24, NO. 3, AUGUST 2009

[8] Heloisa Teixeira Firmo and Luiz Fernando Loure iro Legey,"Generation Expansion Planning: An Iterative Genetic Algorithm Approach" IEEE Trans. Power. Syst., VOL.17, NO.3, AUGUST 2002;

[9] Jong-Bae Park, Young-Moon Park, Jong-Ryul Won, and Kwang Y.Lee, "An Improved Genetic Algorithm for Generation Expansion Planning”, IEEE Trans. Power. Syst., VOL.15, NO.3, AUGUST 2000;

[10] Pinar Kaymaz, Jorge Valenzuela and Chan S. Park,"Transmission Congestion and Competition 
on Power Generation Expansion", IEEE Trans. Power. Syst., VOL. 22, NO. 1, FEBRUARY 2007

[11] B.A lizadeh S. Jadid, "Reliability Constrained Coordination of Generation and Transmission Expansion Planningin Power Systems using Mixed Integer Programming", IET Gener. Transm. Distrib.,Vol.5, Is s.9, JAN 2011, pp.948-960;

[12] Wang, X., Mc Donald, J. R.'Modern power system planning' (Mc Graw-Hill, 1994);

[13] P.Murugan, S.Kannan, and S.Baskar "Application of NSGA-II Algorithm to Single-Objective Transmission Constrained Generation Expansion Planning", IEEE Trans. Power. Syst., VOL.24, NO.4, NOVEMBER 2009

[14] Jizhong Zhu, "Optimization of Power System Operation", John Wiley \& Sons, Inc., Hoboken, New Jersey, 2009;

[15] I. Goroohi Sardou, M. Banejad, R. Hooshmand, A. Dastfan, "Modified shuffled frog leaping algorithm for optimal switch placement indistribution automation system using a multi-objective fuzzy approach", IET Gener. Transm. Distrib. ,Vol.6, Is s.6, 2012, pp.493-502;

[16] John Grainger, Jr., William Stevenson, McGrawHill, "Power System Analys is", pp. 337-338, 1994

[17] "IEEE reliability test system", IEEE Trans. Power App. Syst., VOL.98, NO.6, November/December. 1979, pp. 2047-2054.

[18] "IEEE reliability test system-96", IEEE Trans. Power. Syst., Vol. 14, NO. 3, August. 1999,pp. $1010-1020$

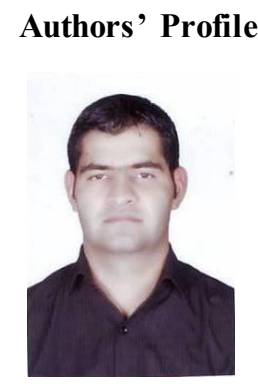

Iman Gor oohi Sardou was born in Jirooft, Iran, in 1986. received the B.Sc. degree in electrical engineering from Shhid Bhonar University, Kerman, Iran, in 2004 and the M.Sc. degree from Shahrood University of technology, Shahrood, Iran in 2006. $\mathrm{He}$ is now a Ph.D student at Abbaspour Technical and Engineering Department, Shahid Beheshti University in Tehran. His research interests include distribution generation and power systemplanning.

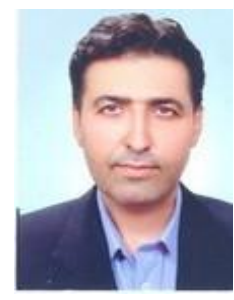

Mohammad Taghi Ameli received BS in Electrical Engineering from Technical College of Osnabruck in Germany 1988. Msc \& PhD from Technical University of Berlin in Germany 1992 \& 1997. Since then He teaches and searches as an Assistant
Professor in Abbaspour Technical and Engineering Department, Shahid Beheshti University. He was general director of areas of research: Power system Simulation, Operation, Planning \& Control of power system.

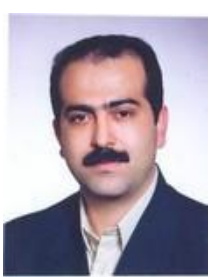

Mohammad Sadegh Sepasian was born in Tehran, Iran, in 1967. He received the B.Sc. degree from Tabriz University, Tehran, in 1990 and the M.Sc. and Ph.D. degrees from Tehran University and Tarbiat Modares University, Tehran, in 1993 and 1999,

respectively.

$\mathrm{He}$ is currently with Abbaspour Technical and Engineering Department, Shahid Beheshti University in Tehran as an Assistant Professor. His research interests include power system planning as well as distribution systemplanning issue.

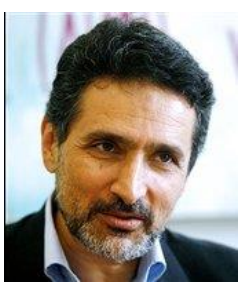

Mohammad Ahmadian was born in Tehran, Iran, in 1956. He received Ph.D.degree from university of Manchester (UMIST), Manchester, England.

$\mathrm{He}$ is currently with Abbaspour Technical and Engineering Department, Shahid Beheshti University in Tehran as an Assistant Professor. His research interests include power system planning as well as power system reliability issue.

How to cite this paper: Iman Goroohi Sardou, Mohammad Taghi Ameli, Mohammad Sadegh Sepasian, Mohammad Ahmadian,"A Novel Genetic-based Optimization for Transmission Constrained Generation Expansion Planning", International Journal of Intelligent Systems and Applications(IJISA), vol.6, no.1, pp.73-83, 2014. DOI: 10.5815/ijisa.2014.01.09 